\title{
ADOLESCÊNCIA: FRATURA E RECONSTRUÇÃO IDENTITÁRIA FRENTE A UM PAI INCESTUOSO
}

Isabella Ferraz Lacerda de Mello

Universidade Federal de Minas Gerais

\section{Cassandra Pereira França}

Universidade Federal de Minas Gerais
Recebido em: 31/07/2020

$1^{\text {a }}$ revisão em: 31/10/2020

Aceito em: 28/11/2020

\section{RESUMO}

O presente artigo tem por objetivo investigar os efeitos de uma verdade impactante, qual seja, a de que o próprio pai é um pedófilo que abusa sexualmente de seus filhos. A partir do viés psicanalítico, tentaremos compreender as reverberações identificatórias quando essa sentença é proferida durante a adolescência do sujeito - o que, sem dúvida alguma, irá tornar caótico todo o processo de elaboração do luto pela perda dos pais idealizados na infância. Apesar de não ter sido a vítima direta do pai, saber que um irmão foi molestado provoca no adolescente uma decepção ímpar. Através de um caso clínico de uma adolescente, acompanhada por uma equipe multidisciplinar, em um hospital público de alta complexidade da cidade de Buenos Aires, especializado no atendimento de crianças e adolescentes vítimas de abuso sexual, tentaremos abrir questões acerca das fraturas psíquicas e suas sequelas no reordenamento identificatório que acompanha a adolescência.

Palavras-chave: adolescência; identidade; abuso. 


\title{
ADOLESCENCE: $\quad$ FRACTURE AND IDENTIFICATORY REARRANGEMENT BEFORE AN INCESTUOUS FATHER
}

\begin{abstract}
The object of this study is to investigate the effects of an impressive truth, wich is the allegation that a person's own father is a pedophile who sexually abuse their children. From the psychoanalytic bias, we will try to understand the identificatory reverberations generated when this fact is revealed during the adolescence of the individual, which will, undoubtedly, turn the grieving process for an idealised parental loss in childhood into a chaotic experience. Although this person was not the direct victim of his father, acknowing that his brother was molested cause adolescent an odd disappointment. Through a clinical case of a teenager, who was accompanied by a multidisciplinary team in a highly complex public hospital in the city of Buenos Aires, specialized in caring for children and adolescents who are victims of sexual abuse, we will try to present questions about psychological fractures and their sequelae in the identificatory rearrangement that accompanies adolescence.
\end{abstract}

Keywords: adolescence; identity; abuse. 


\section{ADOLESCENCIA: FRACTURA RECONSTRUCCIÓN IDENTITARIA ANTE UN PADRE INCESTUOSO}

\section{RESUMEN}

Este artículo tiene como objetivo investigar los efectos de una verdad impactante, a saber, que el propio padre es un pedófilo que abusa sexualmente de sus hijos. A partir de la perspectiva psicoanalítica, intentaremos comprender las reverberaciones identificatórias cuando se pronuncia esta sentencia durante la adolescencia del sujeto, lo que, sin duda, hará que todo el proceso de duelo por la pérdida de los padres idealizados en la infancia sea caótico. Aunque no ha sido la víctima directa del padre, saber que un hermano ha sido molestado causa al adolescente una decepción impar. A través de un caso clínico de una adolescente, acompañada por un equipo multidisciplinario, en un hospital público de alta complejidad en la ciudad de Buenos Aires, especializado en el cuidado de niños y adolescentes víctimas de abuso sexual, intentaremos abrir preguntas respecto a las fracturas psíquicas y sus secuelas en el reordenamiento identificatorio que acompaña la adolescencia.

Palabras clave: adolescencia; identidad; abuso. 


\title{
INTRODUÇÃO
}

\author{
Temos, todos que vivemos, \\ Uma vida que é vivida \\ E outra vida que é pensada, \\ E a única vida que temos \\ É essa que é dividida \\ Entre a verdadeira e a errada. \\ Qual, porém, é a verdadeira \\ E qual errada, ninguém \\ Nos saberá explicar; \\ E vivemos de maneira \\ Que a vida que a gente tem \\ É a que tem que pensar.
}

Fernando Pessoa

A adolescência é uma das etapas mais importantes e transformadoras na vida dos seres humanos, um processo que se inicia com mudanças biológicas que irão desencadear transformações psíquicas múltiplas e variadas, pois, abruptamente, o jovem é surpreendido com mudanças corporais que vão lhe cobrar a busca de uma nova identidade, de um novo lugar na sociedade e que implica o fim da ingenuidade infantil, como demarca Kancyper (2007).

Mergulharemos na temática da adolescência resgatando, inicialmente, algumas ideias desenvolvidas pelos psicanalistas argentinos Arminda Aberastury e Mauricio Knobel, num livro clássico, "Adolescência Normal", que, na década de 1970, introduziu no Brasil algumas reflexões psicanalíticas importantes para se pensar a prática clínica com essa faixa etária. Partindo da necessidade de reconhecermos a síndrome da "anormalidade" da normalidade adolescente, os autores defendem a presença de condutas patológicas na adolescência como necessárias para que o jovem possa desenvolver-se e alcançar a estabilização das "verdadeiras perdas de personalidade" (Knobel, 1970/1981, p.10). Tais perdas precisarão ser acompanhadas pelo enfrentamento de importantes lutos: o luto pelo corpo de criança, o luto pelo papel e identidade infantil e o luto pelos pais da infância (Aberastury \& Knobel, 1970/1981b). Recuperemos um pouco mais o que nos diziam esses autores.

As modificações corporais na adolescência causam um grande impacto no jovem. Para ele, enfrentar essa transformação na própria pele é viver a experiência inicial de não se reconhecer e não reconhecer seu corpo como algo que lhe pertence. Tamanha confusão vem acompanhada de mudanças psicológicas importantes, que pedem um rearranjo libidinal e psíquico para esse novo corpo carregado de expectativas, medos e angústias. 
Entretanto, a experiência de ter sido invadido por mudanças corporais incontroláveis pode ser vivida como um "sentimento de despersonalização" (Knobel, 1970/1981, p. 35) extremamente angustiante para o púbere que, após essas transformações, passará a receber nomeações transitórias, que reabrirão a questão: "Onde foi parar o corpo que me pertencia e a criança que todos viam em mim?" Indagação que mostra como "a própria criança precisa de tempo para fazer as pazes com seu corpo, para terminar de conformar-se a ele, para sentir-se conforme com ele" (Idem, p. 19). Portanto, para que esse processo não seja apagado por uma negação maníaca, é necessário um longo e intenso trabalho de luto para elaboração da modificação do esquema corporal e das dimensões representacionais do corpo e do psiquismo que foram perdidas.

Seguindo Aberastury (1970/1981a), antes mesmo que o adolescente construa seu próprio sistema de teorias e ideais (componentes importantes na construção da sua identidade e ideologia no mundo social adulto), ele precisará atravessar uma das tarefas mais árduas, qual seja, o trabalho de "desidealização das figuras parentais" (Idem, p.16). Este trabalho faz com que o adolescente se dê conta de que os pais não são exatamente o que ele pensava - percepção que irá produzir, a um só tempo, angústia e desprezo pelos adultos. No entanto, a renúncia aos pais estará vinculada à possibilidade de identificação com eles. De acordo com Aberastury et al. (1970/1981b), a presença das imagens paternas no mundo interno do adolescente servirá de "ponte" tanto para a recepção de influências como para a troca de estímulos com o mundo externo. Apesar de a família ser a primeira expressão da sociedade que exerce grande influência na conduta dos adolescentes, o meio em que vive também "determinará novas possibilidades de identificação, futuras aceitações de identificações parciais e incorporação de uma grande quantidade de pautas socioculturais e econômicas" (Knobel, 1970/1981, p. 51-52)

A experiência de perda da representação do corpo, da identidade infantil e dos pais da infância, é vivida pelo adolescente como uma experiência de fracasso ou impotência diante da realidade externa, como afirma Knobel (1970/1981), e esse sentimento de fraqueza demandará um árduo trabalho psíquico. Assim, para compensar as dolorosas perdas sentidas no seu mundo interno, passarão a entrar em ação poderosos mecanismos de defesa, tais como o fantasiar e a intelectualização, que tentarão resgatar a onipotência infantil perdida. Por um lado, a imaginação toma conta do adolescente e ele passa a fazer planos mirabolantes, dos quais podem surgir mudanças reais e transformadoras no mundo em que vive. Por outro lado, através do movimento de intelectualização, o indivíduo fará uma espécie de reajuste emocional e começará a implicar-se em assuntos que antes não despertavam seu interesse e a buscar explicações teóricas para as problemáticas e valores sociais, como as questões políticas e religiosas, os princípios éticos, o amor, a liberdade e a educação.

No processo de rearranjo identificatório, sabemos muito bem como a história das relações objetais da infância vão ter um peso significativo. Assim, a pré-existência da internalização de imagens parentais positivas e com papeis bem definidos 
"permitirá uma boa separação dos pais, um desprendimento útil, e facilitará ao adolescente a passagem à maturidade, para o exercício da genitalidade no plano adulto" (Idem, p. 57), de modo que a figura idealizada de um pai bom e poderoso permitirá que o adolescente identifique-se com os aspectos positivos do pai e supere o temor à castração. Por outro lado, no caso da menina, ela poderá aceitar seus atributos femininos a partir da identificação com os aspectos positivos de sua mãe, superando o medo de ter o corpo destruído ou esvaziado (Knobel, 1970/1981). No entanto, se tiver ocorrido a situação inversa, ou seja, se os papeis das figuras parentais não tiverem sido bem definidos e estáveis, pode acontecer uma desvalorização radical desses modelos por parte do adolescente que, forçosamente, terá de buscar outros modelos identificatórios mais sólidos, de maneira compensatória ou idealizada.

Na puberdade fica mais aguçada uma percepção do que na infância se dava de maneira descontínua: a de que os adultos não são reis e somente são capazes de amparar em escassa medida. Ao aproximar-se do mundo adulto, o adolescente vai descobrir que os adultos não são como pensava - não detêm todo o conhecimento e não podem tudo - e que seus pais, infelizmente, também fazem parte desse grupo. A partir dessa realidade, Rodulfo (2008) explora a ideia de que o adolescente começa a perder os laços fusionais que foram construídos com seus pais e mantidos durante vários anos. Entretanto, como lhe custa muito sentir-se desamparado por aqueles que pensava capazes de the prover de tudo que é necessário para protegê-lo das injustiças e da falta de garantias presentes na humanidade, o adolescente é invadido por angústia e raiva, o que faz com que ele saia em busca de amparo no mundo externo através da inserção social em grupos de pessoas com as quais se identifique. Assim, mesmo criando laços de amizade com outros adolescentes, a intimidade que se cria não tem a mesma intensidade e significado dos laços com os pais, o que pode abrir espaço para a aparição de desintegrações afetivas, como a dissociação e a indiferença afetiva.

A adolescência também é marcada pelo movimento pulsional em que se reatualizam os desejos pré-edípicos e edípicos estabelecendo uma modificação das funções desempenhadas pelo supereu que, anteriormente, no período da latência, exercia a função de proibidor e castigador da atividade sexual, e agora passará a cumprir uma dupla função: "impor novamente o tabu do incesto e, ao mesmo tempo, permitir a sexualidade exogâmica" (Kancyper, 2007, p. 32). O triângulo edípico estabelecido durante a fase genital prévia é reativado de maneira mais intensa na adolescência por causa da realidade factível que a genitalidade impõe ao indivíduo. Não devemos nos esquecer que a vida do sujeito é marcada por duas grandes assinaturas pulsionais: a primeira é assumida na fase edípica, promovendo a inserção da criança na estrutura familiar estável através da apropriação de modelos identificatórios com os objetos primários e, a segunda, na puberdade, com a busca por novos objetos amorosos (Hornstein, 2008). Assim, toda adolescência é marcada pelo esforço da função elaborativa tanto do trabalho de luto pelo corpo e pelos pais da infância, quanto pela reorganização do Eu e das 
instâncias ideais. No entanto, o que acontece quando, em meio a esse turbilhão de afetos e demandas psíquicas, o adolescente tem que lidar com mais um impacto, completamente inesperado: a descoberta de que o pai é um abusador, um pedófilo? E mais, a pessoa de quem ele abusou, não é um estranho, e sim uma irmã ou irmão? E que toda a cena incestuosa se passou bem "debaixo do seu nariz", sem que ao menos se suspeitasse da verdade dos fatos? Quais seriam os efeitos intrapsíquicos desse golpe identificatório? Como o choque traumático ocasionado por essa surpresa, ou melhor, por essa decepção com a figura do pai (de quem se deve descolar na adolescência), poderá interferir no processo de introjeção da imago paterna?

\section{DESENVOLVIMENTO}

A fim de acompanhar os estudos teóricos sobre as questões que acabam de ser apresentadas, a dissertação de Mestrado intitulada "Pai abusador, filho agredido, irmãos marcados: os efeitos da violência sexual na trama fraterna", conduzida por Isabella Ferraz Lacerda de Mello e orientada pela Prof. Dra. Cassandra Pereira França, docente do Programa de Pós-Graduação em Psicologia da Universidade Federal de Minas Gerais, teve como trabalho de campo o acompanhamento em supervisão, durante quatro meses, da escuta psicoterápica (de base psicanalítica) de vários adolescentes que tinham sido marcados por essa problemática. O campo de investigação foi o ambulatório de Saúde Mental da Adolescência do Hospital de Niños Ricardo Gutierrez (Buenos Aires/Argentina), coordenado por Susana Toporosi, psicóloga e psicanalista de crianças e adolescentes.

A fim de emoldurar a problemática que estamos querendo discutir, e de abrir alguns veios teóricos para pensarmos nas sequelas do impacto traumático provocado na estrutura identificatória do adolescente quando ele descobre que o pai é pedófilo e abusa de algum de seus irmãos, selecionamos para apresentação um fragmento clínico de um caso em que se pode constatar o impacto da evidência de um pai perverso na história de uma adolescente de dezessete anos ${ }^{1}$. Seus depoimentos servirão de bússola para guiar-nos na formulação de questões a serem investigadas dentro dessa temática, e na busca de recortes teóricos que possam nos ajudar a pensar nas contribuições de alguns autores sobre o tema.

A garota deu entrada no hospital por tentativa de suicídio: ingeriu uma grande quantidade de medicamentos após uma acalorada discussão entre ela, sua irmã mais velha e seu pai. Observa-se, de imediato, que a pele da jovem estava marcada com grandes cortes, e que seu peso evidenciava um transtorno de conduta alimentar (anorexia). Além dessas marcas, ela revelava sintomas como crises de ansiedade e depressão.

Diante da obscuridade da trama que sustentava o caso clínico, optamos por dar a essa paciente o nome fictício de Clara. A jovem vivia com sua mãe e a irmã mais 
velha (por parte de mãe), e não via seu pai há mais de três anos; ela imaginava que ele tinha ido embora por sua culpa, após ela ter lhe dito em uma discussão que não queria mais vê-lo, e ter lhe pedido para que desaparecesse de sua vida. "No era fácil para mí aceptar que se habia ido", relatou a jovem. Na descrição da garota, apesar de ele ser um pai muito afetuoso e amável com ela, era um mulherengo, incorrigível, e escondia muitas coisas. Não era um bom pai, e a relação deles estava permeada por "mentiras y abandono". Nem sabe ao certo, quantos irmãos tinha por parte de pai - talvez uns oito.

Durante o tratamento no hospital, ela demonstrava dificuldades para se relacionar com as outras pessoas que participavam das atividades terapêuticas grupais. Em um episódio, mordeu uma das companheiras e lhe jogou um copo d'água sem motivos aparentes. Apesar de costumar ficar isolada do grupo, revelava ter amigos na internet, inclusive uma namorada virtual, dizendo que não se interessava nem um pouco por vínculo com homens. Muitos profissionais manifestavam dificuldade em lidar com a conduta antissocial dessa paciente, cujas atitudes reivindicatórias e oposicionistas se direcionavam principalmente aos coordenadores dos grupos (homens) que Ihe remetiam a alguma lembrança de seu pai. Dizia sentir muito medo de se parecer com o pai e pedia que lhe contassem tudo relacionado a ele, pois não queria se desestabilizar emocionalmente, surpreendida por algo que the dissessem a seu respeito. Sentia que as pessoas poderiam lhe causar sofrimento e não podia confiar nos homens - prova disso foi a interferência na sua escolha objetal de relacionar-se com outra mulher (ainda que só virtualmente).

Apesar de a mãe de Clara relatar que, anteriormente, as duas tinham uma boa relação, naquela época já não se entendiam mais: a mãe sentia que a filha a tratava de forma ríspida e distante, e ela por sua vez, assumia não confiar na mãe por pensar que ela lhe escondia as coisas. Dizia: "Ya tuve bastante con mi papá". Direcionava provocações a ela com frases do tipo: "Vos no te das cuenta de nada, así que no me sorprende", mas não esclarecia a que tipos de situações se referia. Com relação aos cortes, justificava: "era un alivio, como sacar un poco el dolor de la mente. Además, era algo que podía controlar en el descontrol de mi casa".

Após um ano de internação, sua mãe decidiu contar a verdade sobre o sumiço do pai. Clara reagiu com profunda decepção, se irritando muito com a mãe por não ter lhe contado antes e dizendo: "Es um hijo de puta. Nunca lo vi como el tipo que hacía estas cosas". Certa vez, durante seu tratamento, disse "A mí me gustaría que mi papá sea todo malo, sea una mierda. No que tenga las dos cosas, sería mucho más fácil", querendo dizer que era melhor que fosse totalmente mau, do que ter uma parte má e uma parte boa. Muitas vezes se confundia entre sentimentos de amor e ódio ao falar sobre o pai, e algumas vezes dizia que sentia saudades dele. Apesar do claro sinal de que a clivagem egóica estava muito bem instalada nessa jovem, possibilitando que um lado dela o odiasse, e o outro o amasse e sentisse saudades, bem sabemos que essa clivagem representava um obstáculo à reconstrução identitária. Situação que só poderia ser alterada se, ao longo do 
tratamento, fosse possível integrar as partes boas e más do objeto internalizado, no caso, seu pai - ajudando no seu próprio processo de reconstrução identitária.

Apesar de haver um sentimento de decepção enorme diante do abandono do pai e de sua relação com outras mulheres, o peso da quebra do tabu do incesto pesava também sobre os seus ombros, mostrando a fratura que produzia em seus processos identificatórios. Tal fratura ficava evidenciada pelo fato de Clara não conseguir conversar sobre o ocorrido com a irmã, pois, cada vez que a olhava, não conseguia sustentar o olhar, sentia-se representante do pai e não podia acreditar no que ele fez. Dizia que apesar de saber de todas as coisas ruins que ele havia feito, ela não imaginava que seria capaz de algo tão monstruoso como abusar de sua enteada - evidenciando que mesmo entre os jovens, o incesto é visto como o pior dentre todos os crimes que uma pessoa pode cometer. No início não aguentava nem ouvir o nome do seu pai, se angustiava muito e dizia que "Hay cosas que los adultos no poden hacer". Se antes brigava muito com a irmã, depois que Clara ficou sabendo do que seu pai fez, passou a ser mais compreensiva com ela e, aos poucos, as relações familiares foram melhorando e, assim, os laços sociais fora de casa também.

Nos casos de abuso sexual intrafamiliar, a fratria parece possuir a força necessária para validar os fatos abusivos que até então haviam sido encobertos pelo mecanismo do "desmentido" familiar. E, muitas vezes, a função exercida pelos irmãos nos faz pensar no papel de suplência que os filhos acabam realizando quando os pais ou responsáveis fracassam como instâncias superegóicas. Percebíamos a incidência de mecanismos denegatórios nessa família e que abriam uma série de questões: por que a mãe, mesmo tendo a informação de que o companheiro, no passado distante, havia engravidado uma adolescente de treze anos (filha de sua última companheira), decidiu nada contar às filhas, deixando-as, às vezes, sozinhas com ele, quando viajava a trabalho? Será que Clara nunca desconfiou de nada, já que os abusos aconteciam no banheiro, quando estavam os três em casa? Por que essa mãe jamais o denunciou? A hipótese diagnóstica da equipe hospitalar acerca dessa composição familiar era a de que havia um par parental composto por um pai perverso e uma mãe borderline. Sendo assim, aonde as filhas poderiam buscar espelhamento e amparo?

O médico psicanalista Luis Kancyper (2007) ressalta a opinião de vários psicanalistas os quais veem a "desestruturação temporária do Supereu" (p.34) na adolescência como consequência do medo que o eu sente de que o Supereu seja um objeto incestuoso e, portanto, uma ameaça, sendo necessário afastar-se não somente dele como também abrir mão dos antigos laços incestuosos com os pais, o que também significa perder parcialmente um objeto amoroso. Contudo, o adolescente também precisa abnegar-se das ordens éticas e ideais correspondentes ao Ideal do Eu e que se encontram muito ligadas ao objeto incestuoso, para que possa fazer uma revisão dos padrões pré-estabelecidos e formar suas próprias opiniões e ideais de si mesmo levando-o à construção progressiva da sua própria visão de mundo. 
Por isso é necessário que aconteça um processo de reorganização das identificações ${ }^{2}$ durante a adolescência. Segundo Kancyper (2007), esse processo será a condição de liberdade frente à identificação que aliena o psiquismo e impede que o desejo de ser circule livremente. Assim, o adolescente poderá ter a chance de construir seu próprio futuro. Alguns laços afetivos deverão ser desfeitos, deixando espaço para a construção de novos laços, "reabrindo o acesso à configuração de novas identificações, em uma reestruturada dimensão afetiva, espacial e temporal" ${ }^{3}$ (p. 37). Uma das maneiras pela qual o adolescente tentará buscar identificações é através da convivência em grupo, conforme marca Paladino (2005), "permitindo uma experimentação interacional como uma atitude de rompimento das dependências infantis" (p. 66).

Outra mudança nessa etapa está relacionada à responsabilização dos próprios comportamentos pelo adolescente. Quando criança, sua conduta era regida pela responsabilidade dos seus pais ou responsáveis, pelo Supereu deles, e agia de maneira a não ser castigado ou para evitar correr o risco de perder o amor dos pais, enquanto na adolescência o jovem começa a entender que suas atitudes têm consequências e ele é quem deve se responsabilizar pelos seus atos, sendo dependente do seu próprio supereu como regulador de suas ações. Para alcançar a independência dos pais e irmãos e garantir uma maior diferenciação, "seu Supereu necessita desprender-se das primeiras relações de objeto, suavizando as imagos parentais proibidoras e reconciliando-as com outras, de pais mais reais, sexualmente ativos, permissivos, que confirmem sua identidade sexual" ${ }^{4}$ (Kancyper, 2007, p. 33).

Diante desse cenário, o adolescente também terá que passar pela experiência de confrontação generacional com seus pais e irmãos para desfazer-se de aspectos alienantes de algumas identificações. Esse movimento colocará em risco o vínculo entre depositante e depositário e a organização narcísica de cada um e pode vir acompanhado de "intensos sintomas de angústia de despersonalização ou desrealização por ambas as partes do vínculo" ${ }^{5}$ (p. 19). As fantasias de morte também podem ser ativadas durante a atitude de confrontação como reação à mortificação de algumas instalações narcísicas e queda das imagens idealizadas, como a figura dos pais.

Para Kancyper (2007), quando todos esses trabalhos são possíveis de acontecer, o adolescente tem a oportunidade de reescrever sua própria história a partir do seu passado misterioso que veio à tona e que agora passa a ser integrado e reordenado na sua realidade psíquica. Portanto, a análise dos aspectos metapsicológicos vivenciados pelo jovem durante a puberdade e a adolescência depende da estreita relação das dificuldades atuais com as problemáticas enfrentadas anteriormente, durante a infância e o período de latência. Assim, diante dos desafios que o adolescente terá de enfrentar, alguns deles podem ser considerados novas batalhas, outros, resquícios de antigos combates. 
Após termos visualizado a extensão das fraturas no processo identificatório dessa jovem, gostaríamos de tecer algumas considerações que levam em conta o quanto o trabalho de reordenamento identificatório é bem mais complexo do que parece, e está em relação direta com dois outros processos: o de historicização, e o de ressignificação - que, com certeza fazem parte do encaminhamento de um processo analítico. Conforme ressalta Kancyper (2007), o primeiro deles, o processo de historicização, engloba um movimento narcisista de "apropriação-intrusão", que acaba forçando o indivíduo a uma adaptação alienante quando se vê obrigado a identificar-se, inconscientemente, com a história dos seus pais. Isso impede que haja espaço psíquico para que o jovem desenvolva sua identidade em liberdade, em um espaço discriminado, sem a intromissão e o empoderamento dos outros. Intrinsecamente ligado ao processo de historicização encontra-se o processo de ressignificação (a posteriori), tal como foi introduzido por Freud, em 1896, no artigo "A hereditariedade e a etiologia das neuroses". Segundo Kancyper (2007), "a ressignificação do traumático acontece durante todas as etapas da vida - porque o trauma tem sua memória e a conserva -, mas explode fundamentalmente durante a adolescência" ${ }^{6}$ (p. 19). Nessa etapa, as cenas traumáticas relacionadas às vivências com os progenitores e irmãos que se encontram suprimidas e não significadas na história do sujeito vem à tona, contribuindo para o aumento das tensões durante esse período. Daí a importância da ressignificação daquilo que não pôde ser significado nas etapas anteriores e de se construir uma nova compreensão do significado dos eventos traumáticos, para que o adolescente possa alcançar o reordenamento das identificações e a confirmação de sua identidade.

O embaraço psíquico provocado na jovem adolescente após os eventos traumáticos chama nossa atenção para a possibilidade de produção de modos de funcionamento mental em que a Verleugnung tenha uma presença marcante. Essa temática é muito bem trabalhada por Figueiredo (2003) o qual percebeu que nas pessoas em que é possível constatá-la estava presente, por um lado, a capacidade de registro e armazenamento de aspectos importantes da realidade interna e externa, além da habilidade para comunicar o que haviam captado nos outros e em si mesmos, nas diversas situações vividas, principalmente aquelas mais difíceis e dolorosas. Por outro lado, apresentavam a tendência de não tirar conclusões desses elementos e de não ser capazes de integrá-los uns aos outros e assim ter uma visão conclusiva da realidade própria e alheia. São pessoas que acumulam e armazenam os elementos no psiquismo, que se repetem insistentemente, porém excluem a influência deles na tomada de decisões e posições favoráveis. Octave Manoni traduziu bem essa situação na frase já citada "Eu sei, mas mesmo assim...". Eles sabem, mas mesmo assim, o que fazem de útil com esse saber? "Conservamse dotados, simultaneamente, de um saber que os torna muito desconfiados e sem esperança e, de uma ingenuidade e falta de experiência que os deixa permanentemente à mercê de 'surpresas' e novos traumatismos" (Figueiredo, 2003, p. 58). 
Algumas áreas de contato com a realidade parecem preservadas nessas pessoas, e nelas as capacidades de conexão e discriminação operam muito bem, revelando que aqui a tomada de decisões é possível operar com eficiência. Outras dimensões da realidade, ao contrário, parecem muito comprometidas. Parece haver uma resistência proveniente daqueles elementos que são percebidos, guardados e relatados repetitivamente; nas palavras de Figueiredo (2003), "não se trata de nãover e de não-lembrar como forma de resistência, mas de, ao contrário, fazer dessas percepções e lembranças recorrentes um empecilho ao progresso da vida" (p. 58).

Seguindo as ideias do autor, o mecanismo da Verleugnung, localizado por Freud como elemento central no fetichismo e na psicose, além de ser uma defesa básica presente na constituição normal do psiquismo infantil, é melhor entendido como "desautorização", pois, através desse termo, é possível destacar um aspecto fundamental desse mecanismo, o da "interrupção de um processo pela eliminação da eficácia transitiva de um dos seus elos" [itálicos do autor] (p. 59). Para o autor, a recusa nos remete a uma dimensão temporal e processual do psiquismo, pois 0 que se recusa é o que vem ou viria depois de uma dada percepção. Não se nega o que se vê, mas as possíveis inferências que o psiquismo possa ter a partir daquilo que se vê. De acordo com Figueiredo (2003), na fórmula "Eu sei, mas mesmo assim...", "o 'eu sei' não é puramente ou liminarmente desmentido; o que se impede é a consequência dessa saber; nessa medida, o 'mesmo assim...' aponta para a preservação de uma posição subjetiva que não pode ser alterada" [itálicos do autor] (p. 60). E como a psicanálise entende a percepção e a possibilidade de sua desautorização? Para ele, uma percepção se caracteriza basicamente por sua capacidade de dar lugar a outras percepções. Inicialmente, a desautorização não incide sobre a percepção propriamente dita, mas do que dela pode vir, como outras percepções e outros processos psíquicos. A recusa não admite novas percepções e acaba desautorizando a "capacidade de uma percepção transitar para outras conservando uma certa continuidade" [itálicos do autor] (p. 61).

Dessa forma, nos deparamos com uma perda da eficácia de uma percepção quando essa é desautorizada, porque sua capacidade de engendrar outras percepções ou a possibilidade de levar uma dada sequência perceptiva a certas conclusões e reativar lembranças é comprometida. Diante da desautorização, "a percepção não perde significado (...), mas perde significância" [itálico do autor] (Figueiredo, 2003, p. 61). Com isso, entendemos que não há uma obstrução total do processo de simbolização, apenas parcial, por causa desse desvio no percurso. O que acontece é que uma parte da cadeia de associações é retirada e identificada como uma "quase-coisa", em que itens colecionam lembranças que se encontram dissociadas do fluxo psíquico porque perderam a capacidade de metaforização e, portanto, de interpretação. Sintetizando essas ideias com o próprio autor, "uma desautorização da eficácia transitiva refere-se ao que já pôde se configurar e entrar, parcialmente, no campo do sentido" (p. 62).

Parece-nos importante explicar o funcionamento do processo de uma percepção propriamente dita. Para Figueiredo (2003), uma percepção desse tipo 
necessariamente deve passar por três momentos: um primeiro momento de síntese, que gera formas, produz certo fechamento que demarca e fornece figurabilidade a algo; um segundo momento, em que ocorre o desfazimento das figuras fechadas e formadas no momento anterior, permitindo a articulação das figuras percebidas com outras figuras; e um terceiro momento, novamente de síntese, o qual garante a continuidade, fluência e transitividade do processo perceptivo, sendo aquilo que se mostra como "realidade" em termos fenomenológicos. "A chamada 'recusa da realidade' é, assim, a recusa dessa última dimensão transitiva do processo perceptivo" (Figueiredo, 2003, p. 63). Como numa cadeia em que cada percepção por si só se torna significante e abre portas para o campo das memórias e expectativas nas quais operam os processos de representação. Dessa forma,

A percepção desautorizada retém um potencial traumático imenso, ao mesmo tempo que tem sua eficácia transitiva abolida. Quanto mais impactante o objeto de uma percepção, maior o seu potencial disseminativo e metafórico, mais percepções novas ela será capaz de gerar, mais elos serão acionados e novas trilhas das redes associativas serão abertas e investidas. (...) Se esse potencial disseminativo não puder ser minimamente metabolizado, se as transições forem por algum motivo obstruídas, dá-se uma experiência de digestão difícil e traumática" (Figueiredo, 2003, pp. 63-64).

A relação da desautorização com o traumático nos interessa principalmente no ponto em que provoca o retorno repetitivo das "quase-coisas" geradas pela desautorização, impedindo a elaboração da experiência traumática. Conforme os escritos do autor, esses materiais chegam ao psiquismo de forma indigesta e descontrolada, provocando um grande embaraço que, em casos menos graves, pode soar ao sujeito apenas como um estado crônico de confusão, mas, nos casos graves, pode assumir um caráter demoníaco ou persecutório, gerando uma sensação de estar sendo ameaçado constantemente.

Quando inserimos a fórmula "eu sei, mas mesmo assim..." no clima nebuloso que comentamos acima, todo o saber é posto em dúvida quanto a sua capacidade de levar a algum lugar, a alguma conclusão ou decisão, "embora na sua realidade mesma seja um saber irrecusável" (Figueiredo, 2003, p. 65).

Podemos observar que o funcionamento do mecanismo da Verleugnung também está presente no caso da adolescente que descrevemos como uma defesa contra a angústia, uma tentativa de manter as experiências traumáticas e os sentimentos associados apartados no psiquismo. Contudo, para o psicanalista Ricardo Rodulfo (2015), a renegação trata-se de algo que vai além da defesa; é um processo, uma forma de funcionamento em que há um desdobramento de duas ideias: sei uma coisa, mas creio em outra e posso manter as duas visões sem que seja necessário 
reprimir alguma delas ${ }^{7}$. Ao parafrasear Mannoni, poderíamos aplicar em sua frase a ideia "Eu sei que dói saber que meu pai não é aquilo que eu sonhava, mas mesmo assim eu o amo".

Neste caso, poderíamos pensar no mecanismo da renegação também como uma saída positiva de maior tolerância à realidade, uma saída criativa diante da dor? Uma tentativa de ter esperança a partir da crença, a qual é preferível manter a reconhecer a dureza da realidade e me render a ela? Ricardo Rodulfo trabalha a crença como importante ativadora da criatividade e, para ele, "sem ilusão a relação com a realidade é sem sentido" ${ }^{8}$, pois manter uma crença também significa manter a ilusão de que há esperança de vida mesmo diante da adversidade.

Além disso, a recordação das decepções causadas pelos pais e o sentimento de culpa despertado pela ação traumática após a descoberta dos fatos, parecem ser uma presença constante no psiquismo da jovem cuja história acompanhamos. Foi possível perceber, pelos relatos dos terapeutas que a acompanhavam que, ao mesmo tempo em que ela demonstrava se sentir culpada pelo dano causado à sua irmã, também culpava e responsabilizava seus pais pelo sofrimento que sentia e que parecia não ter fim. Um tipo de sofrimento com um caráter interminável, e que nos remete à ideia de haver se formado um ressentimento ${ }^{9}$ que poderia corroer a sua existência. Ou será que poderíamos imaginar que, se acaso essa jovem continuasse engajada e comprometida com o seu tratamento psicoterápico, elaborando o processo de historicização e de ressignificação dos fatos, poderia um dia se livrar desse pesado fardo do ressentimento? Se o ressentimento é a repetição ativa do sentimento que traz sofrimento, mantida pelo próprio ofendido, chegaria o dia em que Clara esqueceria o mal sofrido? Ou o seu psiquismo ficaria para sempre tomado por ruminações acusadoras e recordações dolorosas que vêm acompanhadas do desejo de vingança que, apesar de nunca se realizar em ato, continua recorrente em pensamento?

No livro em que se debruça sobre essa temática, Kehl (2014) nos diz que o sujeito ressentido permanece instalado no seu rancor porque, por um lado, esse afeto the oferece um estado de satisfação narcísica ao elevar o sentimento de si e promover uma forma de coesão egóica e, por outro, possui finalidades defensivas ao amenizar os efeitos desestruturantes sobrevindos de outros afetos que também ameaçam o sujeito com a possiblidade de perda da sua organização psíquica. Assim, duas atitudes psíquicas coexistem no eu do sujeito ressentido e fazem frente à realidade externa que se revela contrária à exigência pulsional. Sabemos que é através da clivagem (enquanto mecanismo de defesa) que o eu tenta se defender da excitação massiva e também, evitar a ruptura com a própria realidade, de modo que o ressentido se encarrega de atribuir ao outro a responsabilidade pelo que the faz sofrer. $O$ outro passa a ser o alvo da raiva que sente e da qual não consegue se desfazer, mantendo viva, em fantasia, uma vingança sempre adiada. 


\section{CONSIDERAÇõES FINAIS}

O ressentimento parece formar um lugar de segurança psíquica para onde o sujeito pode recorrer, quando sente que precisa refugiar-se da realidade. Se pensarmos em consonância com essa ideia da autora, teríamos de rever a nossa expectativa de que o ideal seria que o processo psicoterápico desembocasse no fim do ressentimento? Enfim, gostaríamos de entender o destino dos processos de análise desses jovens que descobrem, durante a adolescência, que o pai (até então idealizado) é um verdadeiro abusador de mulheres, e que não respeita nenhum tipo de interdição cultural. Quais as consequências desse choque na vida desse sujeito em plena construção da identidade? Qual é a extensão da força disruptiva no psiquismo do jovem? Apesar de sabermos que a clivagem é um destino inevitável, mesmo que esse processo psíquico demande uma enorme energia do Eu e cause o empobrecimento dessa instância psíquica, gostaríamos de fazer um inventário de quais seriam os pontos de desafio para uma análise, quando ela precisa acompanhar um sujeito que tenha atravessado esses desígnios. Nesse momento, finalizamos essas indagações com uma citação de Mandelbaum (2014), que não nos deixa esquecer a importância da elaboração e do perdão para que o ciclo da violência não seja mantido de geração em geração:

A experiência de um pai ou de uma mãe violentos não isenta cada membro da família de erguer um pai e uma mãe bons dentro de si. Isto é fundamental para que o ciclo da violência não se prolifere no suceder das gerações. A violência é traumática e, portanto, tende à repetição. Daí a necessidade de perdoar os pais. O perdão às vezes é uma tarefa quase impossível, mas esta é a grandeza da elaboração. Elaborar criticamente é também uma forma de perdoar (pp. 44-45).

\section{REFERÊNCIAS}

Aberastury, A. (1981a). O adolescente e a liberdade. In: Aberastury, A., \& Knobel, M. (Orgs.) Adolescência Normal. (pp. 13-23). Porto Alegre: Artes Médicas. (Trabalho original publicado em 1970).

Aberastury, A., Dornbusch, A., Goldstein, N., Knobel, M., Rosenthal, G., \& Salas, E. (1981b) Adolescência e psicopatia. In: Aberastury, A., \& Knobel, M. (Orgs.) Adolescência Normal. (pp. 63-71). Porto Alegre: Artes Médicas. (Trabalho original publicado em 1970).

Figueiredo, L. C. M. (2003). Verleugnung. A desautorização do processo perceptivo. In: Psicanálise: elementos para a clínica contemporânea. (pp. 57-75). São Paulo: Escuta.

Freud, S. (1996). A hereditariedade e a etiologia das neuroses. In: Edição Standard Brasileira das Obras Completas de Sigmund Freud (Vol. 3, pp. 141-155). Rio de Janeiro: Imago. (Trabalho originalmente publicado em 1896).

Hornstein, M. C. R. (2008). Entre desencantos, apremios e ilusiones. Barajar y dar de nuevo. In: Hornstein, M. C. R. (Compiladora) Adolescencias: trayectorias turbulentas. (pp. 117-135). Buenos Aires: Paidós.

Kancyper, L. (2007). Adolescencia: el fin de la ingenuidad ( $1^{\mathrm{a}}$ ed.). Buenos Aires: Lumen.

Kehl, M. R. (2014). Ressentimento (4ª ed.). São Paulo: Casa do Psicólogo. 
Knobel, M. (1981). A síndrome da adolescência normal. In: Aberastury, A., \& Knobel, M. (Orgs.) Adolescência normal. (pp. 24-62). Porto Alegre: Artes Médicas. (Trabalho original publicado em 1970).

Mandelbaum, B. (2014). Terror em casa: a dinâmica da violência no interior do organismo familiar. In: França, C.P. (Org.) Tramas da perversão: a violência sexual intrafamiliar. (pp. 33-46). São Paulo: Escuta.

Paladino, E. (2005). Os discursos sobre a adolescência. In: Paladino, E. O adolescente e o conflito de gerações na sociedade contemporânea. (pp. 51-102). São Paulo: Casa do Psicólogo.

Rodulfo, R. (2008). Vida, no vida, muerte: dejando la niñez. Preludio y fuga a tres voces. In: Hornstein M. C. R. (Compiladora) Adolescencias: trayectorias turbulentas. (pp. 99-116). Buenos Aires: Paidós.

\section{AGRADECIMENTOS}

As autoras agradecem ao Hospital de Niños Gustavo Gutierrez (Buenos Aires, Argentina) especialmente às colegas Susana Toporosi e Adriana Franco, pelo apoio e incentivo às pesquisas do Projeto CAVAS/UFMG.

\section{CONFLITOS DE INTERESSES}

Não há conflitos de interesses.

\section{FINANCIAMENTO}

Conselho Nacional de Desenvolvimento Científico e Tecnológico (CNPq).

\section{SOBRE AS AUTORAS}

Isabella Ferraz Lacerda de Mello é psicóloga, Mestre em Psicologia (Estudos Psicanalíticos) pelo Programa de Pós-graduação em Psicologia da Universidade Federal de Minas Gerais. E-mail: ferrazisa@gmail.com

\section{(iD) https://orcid.org/0000-0002-0399-7884}

Cassandra Pereira França tem doutorado e pós-doutorado pela PUC/SP. É docente e orientadora do Programa de Pós-Graduação em Psicologia da Universidade Federal de Minas Gerais.

E-mail: cassandrapfranca@gmail.com

\section{(iD) https://orcid.org/0000-0003-1528-8214}

\footnotetext{
${ }^{1}$ A adolescente foi acompanhada pela psicóloga Cynthia Funes e por uma equipe de profissionais composta por psicólogos, terapeutas ocupacionais e psicopedagogos, coordenada pelos terapeutas Thomas Hass e Patrícia de Giovanni, no hospital citado.

${ }^{2}$ Luis Kancyper prefere o termo "reordenamento" das identificações ao termo "desidentificação", pois este último lhe parece mágico (comunicação pessoal, 03 de setembro de 2015).

3 "Lo cual reabre el acceso a la configuración de nuevas identificaciones, en una reestructurada dimensión afectiva, espacial y temporal."

4 "Su superyó necesita desprenderse de las primeras relaciones de objeto, suavizando las imagos parentales prohibidoras y reconciliándolas con otras, de padres más reales, sexualmente activos, permisivos, que lo confirmen en su identidad sexual."
} 
5 "Intensos síntomas y angustias de despersonalización o desrealización por ambas partes del vínculo."

6 "La resignificación de lo traumático acontece durante todas las etapas de la vida - porque el trauma tiene su memoria y la conserva -, pero estalla fundamentalmente durante la adolescencia."

${ }^{7}$ Ideias apresentadas por Ricardo Rodulfo em aula (Comunicação pessoal, 09 de novembro de 2015).

8 "Sin ilusión la relación con la realidad es sin sentido" (Comunicação pessoal, 21 de setembro de 2015).

${ }^{9} \mathrm{O}$ ressentimento e sua articulação com os valores morais ocupou um lugar de destaque na obra do filósofo alemão Friedrich Nietzsche, porém, apesar da importante contribuição de seus escritos sobre o ressentimento aos trabalhos de outros estudiosos, não faremos uso dessas articulações no presente artigo. 